Fuad Baćićanin

УДК 027.022:004.9(497.11 Нови

Avdija Salković

Пазар)

Emina Selmanović

Narodna biblioteka „Dositej Obradović”

дОИ https://doi.org/10.18485/

Novi Pazar

melissa.2016.15.1.ch19

\title{
VIRTUELNE ZAVIČAJNE ZBIRKE - RAZMJENA KULTURA
}

\begin{abstract}
Sažetak
Digitalizovane zavičajne zbirke, prvenstveno one koje prikazuju kulturno bogatstvo jednog kraja, sa njegovim specifičnostima i karakteristikama, predstavljaju korak ka izgradnji nadnacionalne, nadprostorne bogate virtuelne biblioteke. Novopazarski kraj, mjesto susreta religija i kultura, svoje kulturno naslijeđe tek počinje predstavljati široj naučnoj i kulturnoj javnosti. $U$ ovom radu ćemo, preko dijela digitalizovane zavičajne građe, Divana Ahmeda Gurbija, lista Bratstvo i časopisa Novopazarski zbornik, prikazati kulturni i književni sadržaj Novog Pazara i okoline.

Divanska književnost, koja se na prostoru Balkana razvijala u periodu osmanske uprave, dala je veličanstvena književna ostvarenja. Jedan od najpoznatijih divanskih pjesnika kod nas je Ahmed Gurbi koji je u 18. vijeku u Novom Pazaru napisao Divan na osmanskom jeziku, a sastavnio dio Divana čini i Kasida o Novom Pazaru.

Nedeljni list Bratstvo, koji je u Novom Pazaru izlazio u periodu od 1945. do 1991. godine, obilježio je rađanje, razvoj ali i iščezavanje jednog novog vremena i kulture.

Novopazarski zbornik je časopis čiji je prvi broj izašao 1977. godine, a koji i danas izlazi u izdanju Muzeja „Ras” iz Novog Pazara. Ovaj časopis prvenstveno piše o pravoslavnoj prošlosti Novopazarskoj kraja, ali i njegovim drugim kulturnim, vjerskim i historijskim osobenostima.

Predstavljajući dio digitalizovane zavičajne zbirke u radu ćemo ukazati na značaj virtuelnog upoznavanja i preplitanja kulturnih bogatstava.
\end{abstract}

Ključne riječi: divanska književnost, virtuelna kultura, zavičajne zbirke, historijski izvori.

Novi Pazar, grad koji je osnovao Isa-beg Ishaković, osnivač Sarajeva i Šapca, prema brojnim izvorima podignut je između 1455-1461. godine. Kao godina osnivanja se ipak uzima 1461. godina. Nalazi se u blizini sred- 
njevjekovnog grada Rasa. „Zna se ko je osnivač Novog Pazara i kada je podignut. To je poznati skopski krajišnik Isa-beg Ishaković, a naselje je izgrađeno, smatra se, krajem šezdesetih godina XV veka" (Zirojević 1977: 111). Godine osnivanja Novog Pazara su u najmanju ruku upitne jer teško da bi se jedan grad mogao osnovati i formirati za samo nekoliko godina, a „prema podacima osmanskih izvora, Novi Pazar 1468/69 godine evidentiran je kao šeher, a to je u osmanskoj klasifikaciji, naselje najvišeg stepena, teško bismo mogli prihvatiti tvrdnju da je podignut u navedenom periodu" (Čar Drnda 1974: 77). Centar je i mjesto preplitanja hrišćanske i islamske tradicije i kulture. Nekada poznato trgovačko mjesto, raskrsnica puteva ima o čemu da govori, ali je bogata građa iščezla i u velikoj mjeri ne istražena.

Kao i brojne biblioteke kod nas, prateći razvoj društvenih tehnologija, i Novopazarska biblioteka je 2010. godine započela sa digitalizacijom svoje zavičajne građe. U želji da Novi Pazar, grad susreta i preplitanja kultura, jezika, religija, i u digitalizovanoj biblioteci prikaže svoj identitet, najprije smo odabrali, uložili truda u pronalasku rukopisnog Divana Ahmeda Gurbija kao i brojeva lista Bratstvo koje naša biblioteka nije posjedovala, a zatim i digitalizovali dio građe koji u najboljoj mjeri odslikava kulturni identitet ovoga kraja.

Digitalizacijom Divana Ahmeda Gurbija, poeme divanske književnosti iz XVIII stoljeća, lista Bratstvo koji je počeo izlaziti u jednoj novoj epohi sa kojom je i svoj izlazak završio i Novopazarskog zbornika, časopisa koji i danas objavljuje naučne i stručne radove, napravili smo korak ka izgradnji jedne virtuelne zavičajne zbirke Novog Pazara dostupne naučnoj, ali i cjelokupnoj čitalačkoj javnosti.

\section{Divan Ahmeda Gurbija}

Na prostoru Novog Pazara, u vrijeme osmanske uprave, živjelo je dosta divanskih pjesnika. Prema pisanju Olge Zirojević mnogi ljudi iz naših krajeva su se istakli kao pisci djela iz različitih oblasti nauka, ali je i veliki broj pjesnika koji su pjevali na sva tri orijentalna jezika - turskom, arapskom i perzijskom (Zirojević 2007: 79). Pojedine poeme ovih pjesnika su do danas sačuvane u izvornom rukopisnom obliku, neke u prijepisima, a neke su sačuvane u tragovima ili smo o njima samo čuli. Naša je želja 
bila da digitalizacijom Divana Ahmeda Gurbija, poznatog novopazarskog divanskog pjesnika, ovo djelo trajno sačuvamo od zaborava, ali ga i prikažemo kao primjerak kulturne raznolikosti Novog Pazara. Imena pojedinih divanskih pjesnika našeg prostora su do danas ostala upamćena kao biseri divanske književnosti. Orijentalista Lamija Hadžiosmanović dala je precizno tumačenje pojma divana i vrijeme nastanka divanske književnosti. „Riječ divan potiče iz perzijskog jezika i označava skup, zbir. U književnosti ona označava sabrana djela jednog autora i to najčešće $u$ jednoj knjizi, odnosno predstavlja zbornik poezije pisane po tačno određenim pravilima i uzorima. Divanska poezija je poezija visokih krugova. Može se reći da turska divanska književnost nastaje sa osmanskim dvorom, ali i nestaje sa njim" (Hadžiosmanović 1995: 6). Fehim Nametak za divansku književnost kaže da se formirala „na osnovama stare turske narodne književnosti, pod snažnim utjecajem islamske kulture i već formirane klasične perzijske književnosti" (Nametak 1998: 464).

Među najpoznatije divanske pjesnike Novog Pazara ubraja se Ahmed Vali Novopazarac (1564-1599) koji je živio veoma kratko, a iza sebe je ostavio veliku i poznatu poemu Ljepota $i$ srce $^{1}$ o kojoj se i u njegovo vrijeme, a i danas, mnogo pisalo. Rođen je u Novom Pazaru gdje je i umro u trideset petoj godini života.

Arši Čaki Muhamed, pisao je na perzijskom i turskom jeziku, a najpoznatije su mu dvije kaside kojima slavi i veliča Mehmed-pašu Sokolovića, velikog vezira Osmanskog carstva, odnosno Mustafa-pašu, beglerbega Rumelije. Rođen je u Novom Pazaru, tačna godina rođenja nije poznata, a umro je 1570/71. godine, što odgovara 978. hidžretskoj godini.

Hušui je pjesnik iz Novog Pazara koji je živio i pisao u drugoj polovini XVI i početkom XVII stoljeća. Poznat je po pisanju kasida i hronograma. Najpoznatiji hronogrami koji i danas postoje su natpis na Carevoj ćupriji u Sarajevu kao i natpis iznad ulaznih vrata Novopazarske banje:

„Oni koji su vidjeli Istok i Zapad, kopno i more rekli su: na svijetu mi nismo vidjeli ovakve termalne banje,

$1 \quad$ Ahmed Vali Novopazarac, Ljepota i srce, Novi Pazar: Državni univerzitet u Novom Pazaru, 2009.

$2 U$ divanskoj poeziji mnogi pjesnici imali su pseudonim, odnosno mahlas. Mahlas su dobijali od svog mentora koji je morao biti poznat i već afirmisan pjesnik. Za neke divanske pjesnike, osim njihovog mahlasa i nemamo ostale podatke. 
između njih jedan, vidjevši je, izreče joj zbirni hronogram:

ova banja postade raj za zaljubljene." ${ }^{3}$

Sabiranjem brojčanih vrijednosti slova dolazimo do podatka da je hronogram napisan 1594/95. godine, odnosno 1003. hidžretske godine.

Veliki i poznati novopazarski divanski pjesnik Ahmed Gurbi napisao je Divan u sklopu kojeg je i Kasida o Novom Pazaru. O Dervišu Ahmedu Gurbiju koji je u svom zavičaju poznatiji kao Gurbi-baba u tezkerama ${ }^{4}$ i ostalim izvorima skoro da ne postoji nikakva informacija što u mnogome otežava proučavanje njegove ličnosti i djela. Sve što se može čuti ili pročitati o njemu dobijeno je iz njegovog Divana u kome on na više mjesta navodi svoje ime, pa iz stihova saznajemo da je rođen u Novom Pazaru, kao i da mu se otac zvao Ali.

Moje ime Derviš Ahmed uvijek se kazuje

Alijin sin sam, sav narod ovog svijeta zna.

Moj zavičaj je zemlja Bosna

Sav narod svijeta ovo ime zna.

Moj grad u Novom Pazaru je

Ko slavuj zasjeli u ružičnjaku je. ${ }^{5}$

Tačan datum pjesnikovog rođenja nije poznat, ali se iz stihova njegova Divana može donijeti zaključak. Gurbi je 1135. godine po hidžri počeo sa pisanjem djela i na taj dan je imao 25 godina. Iz ovoga proizilazi da je rođen $1698 / 99$. godine.

Nakon hidžre hazreti Pejgamberove, Bilo je to hiljadu sto trideset i pete godine.

3 Tabla sa ovim tarihom - hronogramom i danas stoji iznad ulaznih vrata takozvane Stare novopazarske banje.

$4 \quad$ Tezkera - biografija.

5 Tekst Divana koji je napisan na osmanskom jeziku arapskim pismom, čije dijelove navodimo u ovom radu, najprije smo transliterirali na latinično pismo, a zatim izvršili i prijevod (prepjev). 
Imao sam dvadeset i pet godina, čestiti, Počeo sam stihom riječi čiste vesti.

U Gurbijevim pjesmama preovladavaju sljedeći pojmovi: Allah, ljubav prema poslanicima, prolaznost ovog svijeta, stremljenje ka susretu sa Allahom, napuštanje ovosvjetskih blagodati, vaspitanje sopstvenog nefsa ${ }^{6}$ i slični islamski termini.

Gurbi je otišao iz Novog Pazara, a turski grad Edirne, nekadašnja prijestonica Osmanskog carstva, bio je mjesto u kom je proveo duži vremenski period. On i o tome govori u Divanu.

Čudno se stanje, o Voljeni, meni dogodilo u zavičaju mom, Krenuo sam u tuđinu, opet voljom ličnom.

U pjesmama Derviš Ahmed koristi mahlas Gurbi, ali ostaje nepoznanica kako i kada je Ahmed dobio svoj mahlas. Kada je riječ o razlozima odabira imena Gurbi, analizom Divana mogu se osjetiti sljedeći nagovještaji:

Ako si derviš Ahmede zašto ti je mahlas Gurbi,

Zato što je želja moja da pronađem Hakka. ${ }^{7}$

Postoje tumačenja da je mahlas - pseudonim Gurbi, koji znači tuđinac, uzeo jer je patio za svojim zvičajem, što može imati smisla ako se uoči koliko je stihova svoga Divana posvetio Novom Pazaru. Međutim, saznanje da je samovoljno otišao iz Novog Pazara, u koji se kasnije vratio, ali i još neki stihovi Divana upućuju nas na potpuno drugačije tumačenje. Derviš Ahmed vjeruje da nije blizak sa Allahom u mjeri u kojoj bi trebao biti, on osjeća da je udaljen od Njega, pa zato život provodi u gurbetu, tj. tuđini, u stalnoj čežnji i potrazi za Istinom. Ako se pođe od ove tvrdnje iz riječi gurbet mogu se izvjesti i značenja poput pad u tuđinu, pripadnost tuđini i sl. U islamskoj literaturi, a posebno u poslaničkim predajama, opisana su slična i još intenzivnija stanja sljedbenika poslanika Muhammeda, neka je mir i spas nad njim.

\section{Nefs - duša, ego.}

El-Hakk - Onaj koji je apsolutna Istina (Allahovo ime). 
Gurbi također koristi i ime Derviš. Riječ derviš potiče od perzijske riječi deryuš - prosjačenje (od vrata do vrata). Međutim, kao tesavufski termin, derviš predstavlja osobu koja se radi Allahove ljubavi odrekla ovosvjetskih blagodati, koja je izabrala siromaštvo i skromnost i koja se obrazuje po pravilima tarikata pod vođstvom nekog učitelja. Po mišljenju ovog divanskog pjesnika dervišluk podrazumjeva nipodaštavanje ovog svijeta, odricanje od ovosvjetskih blagodati, svijest da slava i bogatstvo predstavljaju teret.

O Gurbi, što je više tuge dervišu na svijetu ovome, Znaj toliko smo više imućniji na svijetu drugome.

Derviš Ahmed Gurbi umro je u Novom Pazaru i ukopan je na groblju Gazilar. Tačna godina smrti nije poznata, ali se na tarihu, natpisu na kamenoj ploči koja je uzidana u zid turbeta, može vidjeti da je izgrađeno 1771. godine, što nam kazuje da je umro nešto prije ovog datuma. Pri samom kraju svog Divana Derviš Ahmed Gurbi spominje još jednu godinu $i$ to 1160 . hidžretsku godinu koja odgovara 1747 . godini. To bi bila godina završetka pisanja Divana, ali i dokaz da je Ahmed Gurbi još bio u životu.

Gurbijev Divan sadrži 189 pjesama, pored kojih se u određenim dijelovima nalaze i kur'anski ajeti ${ }^{8} \mathrm{i}$ hadisi ${ }^{9}$. S obzirom da je vjera islam jedan od najvažnijih izvora klasične turske književnosti, u pjesmama se pojavljuju elementi poput ajeta, hadisa, priča o Božijim poslanicima, vjerovanja, legendi, različitih životnih shvatanja i pogleda na svijet. Gurbi pjeva o Stvoritelju univerzuma, o svetim knjigama: Kur’anu, Zeburu, Indžilu i Tevratu, o kur'anskim surama (poglavljima), o meleku (anđelu) Džebrailu, pjeva o poslanicima, pa je u Divanu spomenut Adem, Nuh, Sulejman, Isa, Idris, Musa, Ismail, Ishak, Jahja, Davud, Salih, Junus, Lut, Hud, Muhammed, zajedno sa Hidrom, Ebu Bekrom, Osmanom, Omerom, Alijom, Hasanom i Husejnom. Pjeva o dvanaestorici imama, o vjerskim velikanima poput Sejjida Alija i Hadži Bektaša Velija. Osim vjerskih tema, koji čine dobar dio Divana, spomenuti su i tzv. junaci ljubavi Lejla i Medžnun, Husrev i Širin, Vamik i Azra, zatim i brojne legendarne historijske ličnosti.

$8 \quad$ Kur'anski ajeti - rečenice, odnosno stihovi u Kur'anu.

9 Hadis - predaje poslanika Muhammeda, neka je mir i spas nad njim. 
Zajedno sa naučnim disciplinama kao što su muzika, medicina, astronomija i astrologija, koje predstavljaju jedan od sadržinskih elemenata turske klasične poezije i koji se često sreću u divanskoj poeziji, u Gurbijevom Divanu često se obrađuju teme poput ljubavi, prirode, tesavvufa, čežnje, društvenog života i dr.

\section{Gurbijeva Kasida o Novom Pazaru}

Jedan dio Divana posebno je značajan, jer je pored svoje pjesničke ljepote veoma značajan izvor za proučavanje Novog Pazara, njegovih ljepota, arhitekture, geografskog područja, poljoprivrede, i svakako historije. Derviš Ahmed Gurbi napisao je kasidu o svome rodnom gradu Novom Pazaru u kojoj je detaljno prikazao ljepote ovoga kraja. Kasida o Novom Pazaru ima 61 bejt (distih) i napisana je 1744. godine. O svome gradu Gurbi počinje kazivati stihovima u kojima moli Boga da sačuva njegove stanovnike, a u sklopu ovog rada ćemo predstaviti samo neke stihove kaside.

Novog Pazara osobine moram spomenuti, Njegovi predjeli i narod pod zaštitom su Settara. ${ }^{10}$

Koliko god da je krivaca i griješnika, do svih njih, Nisam bez nade, stići će milost Gaffara. ${ }^{11}$

Dušmane, zlo što smjeraju ovom narodu i gradu našem, Sa nastojanjem upućenih, stići će srdžba Džebbara. ${ }^{12}$

Ako neko jedan pogled zlonamjerni uputi, Gdje god da je, stići će ga sila Kahhara. ${ }^{13}$

Neka Huda ${ }^{14}$ popravi loše i na bolje stanje nek' promijeni, Kod onih koji su grješni, nepokorni, čak i nemoralni.

10 Es-Settar-Onaj koji pokriva nedostatke (Allahovo ime).

11 El-Gaffar - Onaj koji prašta (Allahovo ime).

12 El-Džebbar - Silni, Onaj koji sve narušeno popravlja (Allahovo ime).

13 El-Kahhar-Onaj koji pobjeđuje sve (Allahovo ime).

14 El-Huda-Onaj koji upućuje (Allahovo ime). 
Spominje se kao Medina, ${ }^{15}$ to mu je cijenjeno ime drugo,

Ovim se lijepim imenom zove, u ovom trenu, taj posebni grad...

I nastavlja tako sa molbama za svoj grad, a nakon ove molitve, Ahmed Gurbi poziva čitaoca da posluša o geografskim ljepotama Novog Pazara i šire regije. On pjeva o rijekama koje teku kroz ovaj grad, o česmama čiste vode sa kojih se narod napaja. Pjeva o planinama koje Novi Pazar okružuju, o Rogozni, Mokroj Gori, Kopaoniku i Goliji, o lalama, zumbulima, karanfilima, ljubičicama, narcisima, ružama, o zambacima, šafranima, o rudama kojima Novi Pazar obiluje. O selima i gradskim naseljima bogatim voćem i vinogradima i u jednom bejtu kaže:

Nemoguće je opisati ni hiljaditi dio njegov,

I kada bi mora bila mastilo, a sva drveća pero.

Ahmed Gurbi pjeva o tvrđavama i gradskim utvrđenjima, o kulama, hamamima i poznatim gradskim džamijama. On na kraju kaside moli za narod, za ozdravljenje svih bolesnika, ali se u zadnjim bejtovima vraća sebi i čitaocu, moli ga za oprost jer je njegovih grešaka puno.

Ahmed Gurbi je pjevao i nije puno mislio o tome da se dopadne savremenicima, ali je njegovo djelo do danas ostalo da se iščitava i proučava. Ahmed Gurbi se nadao da će njegova poezija učiniti da ga ljudi ne zaborave, u najmanju ruku da će njegove pjesme izazvati molitve za njegovu dušu, što na kraju i govori. Digitalizacija ovog gotovo zaboravljenog djela dokaz je da su njegova iskrena nadanja ostvarena i da Novi Pazar iz Gurbijevih stihova neće biti zaboravljen.

\section{List Bratstvo}

Prvi broj lista Bratstvo izašao je 1. juna 1945. godine na četiri strane, samo nekoliko dana nakon rođendana Josipa Broza Tita, pa je na naslovnoj strani tekst pod naslovom „Rođendan maršala Tita” bez potpisa autora, ali i tekst pod naslovom „Novi dani” autora Ediba Hasanagića. U ovom

15 Medina - Grad u Saudijskoj Arabiji u kojem je ukopan poslanik Muhammed. 
broju je još nekoliko tekstova o Titu, kao i nekoliko koji pišu o zajedničkom radu i životu građana Novog Pazara i drugih gradova u okruženju. Na samom početku, u svom prvom broju, list Bratstvo je uskladio svoje pisanje sa tadašnjim društvenim tokovima, ali i sa multinacionalnom strukturom stanovništva Novog Pazara.

Prije lista Bratstvo, krajem decembra 1944. godine, izašao je list Vijesti. Zaključno sa 1 . majem 1945. godine štampano je trideset osam brojeva ovog lista. Ovo saznajemo iz teksta koji je objavljen u jubilarnom dvijestotom broju lista.

„Još u decembru mesecu 1944. godine Odeljenje imformacija i propaganda Sreskog Narodno - oslobodilačkog odbora izdalo je prvi broj 'Vijesti'. Do 1. maja 1945. izašlo je 38 brojeva 'Vijesti'. One su redovno obaveštavale čitaoce u Sandžaku o zadnjim naporima naše Armije u borbama za oslobođenje zemlje. Pored toga donosile su i prve vesti o obnovi i izgradnji. 'Vijesti' su posebnu pažnju posvećivale radu u našem kraju" (Bejtić 1956: 4).

U mjesecu maju 1945. godine donijeta je odluka da se umjesto lista Vijesti pokrene list Bratstvo, čiji će se prvi broj pojaviti 1. juna iste godine, a iako je nasljednik Vijesti, lis Bratstvo će izaći od broja 1. „U mesecu maju 1945. godine Odeljenje za agitaciju i propagandu Okružnog komiteta KPJ odlučilo je da umesto 'Vijesti' izdaje povremeni list. Tada je rešeno da se za ime lista uzme prvi deo parole 'Bratstvo - Jedinstvo'. Krajem istog meseca izašao je prvi broj 'Bratstva'”' (Bejtić 1956: 4).

U planu je bilo da se ovaj list pojavljuje iz štampe petnaestodnevno, ali su se često dešavala odstupanja. „List se ponekad ne bi pojavio ni za tri četiri meseca. Nije bilo hartije" (Jelenković 1956: 4).

Dana 20. decembra 1959. godine izlazi 326. broj lista Bratstvo, a naredni broj 327 pojavljuje se iz štampe tek 24. maja 1977. godine. Posljednji broj lista Bratstvo bio je 1047, a izašao je 25. decembra 1991. godine.

Od 1987. godine prestali su da izlaze listovi Jedinstvo iz Sjenice i Tutinske novine iz Tutina. Udružene su snage kako bi list Bratstvo dobio na popularnosti, kvalitetu i snazi.

Od broja 4 Bratstvo ima svoje podnaslove koji su se relativno često mijenjali. Prvi podnaslov lista broj 4, od 15. jula 1945. godine glasio je List Jedinstvenog narodno-oslobodilačkog fronta novopazarskog okruga. Od 
broja 6 koji izlazi iz štampe 17. avgusta 1945. godine podnaslov je glasio List Narodnog fronta Okruga novopazarskog. Dana 14. septembra 1947. godine izlazi broj 52 čiji podnaslov lista glasi: List Gradskog odbora Narodnog fronta. Od broja 114 iz 1952. godine podnaslov glasi List Narodnog fronta srezova: deževskog, studeničkog, štavičkog i sjeničkog, a od broja 126, od 16. marta 1953. godine, podnaslov je List SSRNJ srezova: deževskog, studeničkog, štavičkog i sjeničkog. Godine 1955, počev od broja 173 podnaslov je List Socijalističkog saveza radnog naroda za srez Novi Pazar. Od broja 358, od 10. januara 1978. godine, podnaslov lista Bratstvo je List za društvena i politička pitanja.

Do broja 21 u listu nije bio naveden glavni i odgovorni urednik niti sastav redakcije, da bi već za broj 22, od 1. maja 1946. godine odgovorni urednik bio Rizo Selmanović. Od broja 74 iz 1949. godine urednik je Aleksandar Popović, a već kod broja 80 iz 1949. Miroslav Profilović. Adem Karaahmetović je uređivao Bratstvo od broja 83 do 85 iz 1949. godine, a od broja 86 iz 1950. godine Danilo Barjaktarović. Hrane Karamarković je uređivao list od broja 96 iz 1950. godine. U toku 1951. godine promijenila su se dva urednika, za broj 109 urednik je bio Ramiz Crnišanin, a od broja 110 Miroslav Profilović. Od broja 114 iz 1952. urednik je Asim Kamešničanin, a od 125. broja iz 1953. godine Mehmed Bejtić. Đorđije Popović je uređivao list Bratstvo od broja 193 koji je izašao iz štampe 1956. godine, a od broja 251 iz 1957. za odgovornog urednika je ponovo postavljen Ramiz Crnišanin. Rastko Palibrk je glavni i odgovorni urednik lista Bratstvo od broja 327 iz 1977. pa do broja 543 iz 1981. godine. Od broja 544 glavni i odgovorni urednik je Jugoslav Ćeriman koji je taj posao obavljao sve do juna 1982. godine. Nasljeđuje ga Vladimir Antić od broja 579 koji je iz štampe izašao 2. jula 1982. godine. Zadnja dva glavna i odgovorna urednika lista Bratstvo su Vladeta Palamarević od broja 724 iz 1984. godine pa do broja 1030 i Bisera Vukašinović od broja 1031 iz 1991. godine pa do 1047, koji je i poslednji broj ovog lista.

Zanimljiv detalj za list Bratstvo je da je on počeo izlaziti sa početkom jednog novog vremena kod nas, u Novom Pazaru ali i cijeloj Socijalističkoj Jugoslaviji, ali se sa gašenjem tog vremena i nestajanjem te zemlje i sam ugasio.

List Bratstvo, koji je u Novom Pazaru izlazio u period od 1945. do 1991. godine, obilježio je rađanje, razvoj ali i iščezavanje jednog novog 
vremena i kulture. Kako ni jedna ustanova nije čuvala sve primjerke ovog lista, a ni sama Novopazarska biblioteka nije posjedovala sve brojeve, najprije se uložilo truda da se pronađu brojevi koji nedostaju i da se izvrši digitalizacija ovog vrijednog lista kako bi se sačuvao od zaborava. Biblioteka Novog Pazara je početkom digitalizacije svoje građe, najprije ovog lista, a kasnije još nekih izdanja koje spominjemo u ovom radu, bogatu kulturu svoga kraja dostvaila na uvid širokoj javnosti. lako je u Novom Pazaru tradicionalno mnogo više upotrebljavano latinično pismo, list je štampan na ćiriličnom pismu, ali su tekstovi, u zavisnoti od autora pisani i ekavskim i ijekavskim nariječjem. Sve ovo ukazuje na komunistički pristup suživotu u multinacionalnim sredinama.

Prvi brojevi lista Bratstvo pisali su najviše o jedinstvu bratskih naroda i narodnosti, demokratskim izborima, borcima koji su živote dali za odbranu svoje zemlje, obnovi zemlje, razvoju privrede i poljoprivrede, ali je u svakom broju neizostavna tema bio Josip Broz Tito.

Samo u prvom broju lista koji je izašao 1. juna 1945. godine nekoliko je tekstova o Titu: „Rođendan maršala Tita”, „Maršal Tito na putu kroz Hrvatsku i Sloveniju” i „Naši pioniri proslavljaju rođendan svoga Tita”. Nijedan od ovih tekstova nije potpisan.

Kao uvodnik prvog broja je tekst pod naslovom „Novi dani” autora Ediba Hasanagića. On govori o staroj Jugoslaviji, koja je među ljudima sijala mržnju, i ovoj novoj, koja je domovina svih njenih naroda. Konstatujući da „nije bilo kraja u staroj Jugoslaviji koji je toliko zaostao i u tolikoj mjeri od države zapostavljen, kao što je bio slučaj sa sadašnjim novopazarskim okrugom i Sandžakom uopšte”, ali i nastavlja sa ushićenjem „politiku mržnje, zavađanja i bratoubilačke borbe, pobjedila je politika bratstva i zajedničkog rada. Za Srbe i muslimane našega okruga, koji sačinjava veći dio Sandžaka, ovo je i biće zaista u svemu nov život" (Hasanagić 1945: 1). I u nastavku on govori o problemima kroz koje je muslimanski narod prolazio u bivšoj Jugoslaviji naglašavajući da dolaze novi dani za sve, a posebno za muslimane, a na kraju teksta Hasanagić konstatuje „Naš list Bratstvo treba da bude i biće izraz ogledalo toga života i rada u našem okrugu" (Hasanagić 1945: 1).

Da je list Bratstvo samo nastavak tradicije pisanog informisanja u Novom Pazaru govori Risto Jovanović. On kaže da je list Bratstvo počeo izlaziti poslije rata i nastavlja „To je list koji je nastavio tradiciju napred- 
ne štampe Sandžaka. I pre rata u našem kraju je izdavan i štampan list pod imenom 'Glas Sandžaka'. U predratnim uslovima taj list se nije mogao održati, jer je, tretirajući na napredan način razne probleme ovog kraja bio formalno ugušen od režima. Nemajući materijalnu bazu, a budući napredan, on je bio trn u oku tadašnjim vlastodršcima, pa je zato bio primoran da prestane sa izlaženjem" (Jovanović 1959: 1). Ovaj list je počeo sa narodnooslobodilačkom brobom i parolom širenja bratstva i jedinstva naroda Jugoslavije. U mnogim brojevim ta se parola citirala i stalno napominjalo da se od tekovina revolucije ne smije odustati. „Promena društvenog sistema izraslog iz velikog Narodnooslobodilačkog rata i revolucije, dala je mogućnost da se afirmišu sva napredna shvatanja, da dobiju svoju punu javnost i potvrdu" (Jovanović 1959: 1). List Bratstvo je pisao o svim temama koje su se ticale društvenog života zajednice. Kultura je uvijek zauzimala značajno mjesto, ali i ostale teme nisu bile zanemarene. List je pisao o naprednim ljudima, naprednoj kulturi, naprednom obrazovanju, a oni koji nisu smatrani naprednim nazivani su zaostalim.

Devedesetih godina prošlog vijeka komunizam je bio na izdisaju. List ipak nije htio odustati od svojih postavljenih tekovina. Nije se uklapao u novi društveni sistem, pa nije ni prihvatao promjene. Često su, u zadnjim brojevima lista, objavljivani čak i uvredljivi tekstovi od strane novinara pa i urednika. Sve je to vodilo gašenju lista Bratstvo koji je obilježio jedno vrijeme i bio stub informisanja u Novom Pazaru i šire. Jubilarni hiljaditi broj lista izašao je 16. novembra 1990. godine. Samo jednim kratkim tekstom na naslovnoj strani, uredništvo lista se obratilo čitaocima. „S obzirom na okolnosti i vreme u kojem živimo, u NRIO 'Bratstvu' ovoga puta nije predviđeno nikakvo svečarenje. Radi toga ovaj broj shvatamo kao i svaki drugi, objavljujući uobičajene tekstove po uobičajenom sledu i redosledu" (Bratstvo 1990: 1). Način odnosa uredništva lista prema čitaocima i novonastalom društvenom sistemu, i njihovo nesnalaženje dovelo je do gašenja lista Bratstvo. Zadnji broj je izašao 25. decembra 1991. godine.

\section{Novopazarski zbornik}

Prvi broj Novopazarskog zbornika izašao je 1977. godine u izdanju Zavičajnog muzeja iz Novog Pazara, a urednik je bio Ejup Mušović. Svake 
godine je izlazio po jedan broj ovog zbornika, osim 2005. godine kada se Novopazarski zbornik nije pojavio iz štampe, broj 28 je izašao 2004. godine, a naredni broj 29 štampan je 2006. godine. Posljednji broj Novopazarskog zbornika je 38 za godinu 2015. i u trenutku pisanja ovog rada još nije bio objavljen broj za 2016. godinu.

Pored Ejupa Mušovića, koji je uređivao Novopazarski zbornik zaključno sa brojem 19 za 1995. godinu, od broja 20, pa do broja 25 urednik je bila Dragica Premović-Aleksić. Svetlana Čeković je bila urednik brojeva 26, 27 i 28, a od 29 zaključno sa brojem 37 za 2014. godinu Novopazarski zbornik je ponovo uređivala Dragica Premović-Aleksić. Zbornik za 2015. godinu broj 38 uredila je Jasmina Fortić. Redakcija Zbornika se neznatno mijenjala, a prvu redakciju su pored urednika činili: Jovan Kovačević, Radomir Stanić, Mehmed Bejtić, Dragica Aleksić, Vladeta Palamarević, Blagoje Biševac i Ismet Rebronja.

Godine 1971. na području Novog Pazara započeta su arheološka istraživanja. Ona su obuhvatala kompleks Rasa i dolinu rijeke Raške, a privukla su pažnju tadašnje naučne i stručne javnosti. U uvodnom tekstu prvog broja Novopazarskog zbornika Ejup Mušović navodi da „osim spomenika sakralne prirode: Petrova crkva, Đurđevi stupovi, Kapela kralja Dragutina, Sopoćani, koji su očuvani do naših dana, a indikatori su burne istorije ovoga kraja, očuvani su ostaci Rasa, Jeleča i Deževe, srpskih srednjovekovnih prestonica, a to su upravo mesta u neposrednoj okolini današnjeg Novog Pazara" (Mušović 1977: 3). Kako bi se petogodišnji arheološki radovi na ovom području, koji su započeti 1971. godne predstavili naučnoj i široj javnosti, Zavičajni muzej u Novom Pazaru je u oktobru 1976. godine organizovao Simpozijum o Rasu i spomenicima u dolini Raške na kojem su uzeli učešća najistaknutiji naučnici koji su radili na spomenutim arheološkim istraživanjima. Mušović u nastavku uvodnog teksta govori o tome kako je nastao Novopazarski zbornik i kaže: „Referate koje su podneli na Simpozijumu objavljujemo u ovom Zborniku sa željom da upoznamo širu javnost sa rezultatima arheološko-istraživačkih radova u dolini Raške” i konstatuje da je ovo „prvi broj Novopazarskog zbornika čiji je izdavač Zavičajni muzej, a nadamo se da će njegovo izlaženje biti nastavljeno" (Mušović 1977: 4).

Drugi broj Novopazarskog zbornika predstavlja radove sa XV Savetovanja etnoloških društava Jugoslavije koje je održano u Novom Pazaru od 
22. do 26. septembra 1977. godine. U ovom broju Zbornika samo se tri rada tiču Novog Pazara, jedan Ejupa Mušovića ${ }^{16}$, drugi Breda Vlahovića ${ }^{17}$ i rad Miluna Barjaktarevića ${ }^{18}$. Ostali radovi su tematski potpuno različiti, od onih koji su posvećeni drugu Titu, preko onih koji su posvećeni prošlosti srpskog naroda, do zavičajnih radova različitih krajeva Socijalističke Jugoslavije.

Treći broj Novopazarskog zbornika pojavljuje se 1979. godine, iako prethodno nije bilo nikakve konferencije ili simpozijuma, pa je tako ostvarena nada koju je njegov urednik izrazio u uvodniku prvog broja „da će njegovo izlaženje biti nastavljeno" (Mušović 1977: 4).

Teme kojima se Novopazarski zbornik bavi prvenstveno obrađuju srpsku kulturnu baštinu i bave se pravoslavnom prošlošću Novog Pazara, ali i njegovim drugim kulturnim, vjerskim i historijskim osobenostima. Postoje i brojni tekstovi čije teme nisu u dodiru sa Novim Pazarom ali su našle mjesto u Novopazarskom zborniku. Pored arheologije, umjetnosti, arhitekture, etnologije, etnografije, običaja, folklora, geografije, biografije, bibliografije, istorije, arhivistike, književnosti, jezika, muzike, religije Zbornik se bavi i medicinom, tehnologijom, matematikom, fizikom, hemijom, biologijom, pravom, ekonomijom, politikom, sociologijom, statistikom, filozofijom, psihologijom i drugim naučnim i životnim temama.

Za Zbornik su pisali mnogi naučni radnici među kojima su Olga Zirojević, Vukman Ćulafić, Risto Jovanović, Ejup Mušović, Bogumil Hrabak, Senko Rašljanin, Rasim Muminović, Dragica Premović-Aleksić, Srboljub Živanović, Safet Bandžović, Izudin Šušević, Svetlana Biorac, Zvonimir Kaluđerović, Aleksandar Kadijević, Muradija Kahrović, Husein Derdemez, Đorđe Kostić, Milutin Barjaktarević, Aleksandar Jovanović, Vojislav Jovanović, Jovanka Kalić, Danica Popović, Avdija Avdić, Simon Jovanović, Miodrag Radović, Marko Popović, Zaim Azemović, Husein Derdemez, Redžep Škrijelj, Fuad Baćićanin i drugi.

Apstrakti svih radova u prvim brojevima Novopazarskog zbornika prevedeni su na francuski jezik. U kasnijiim brojevima su neki apstrakti prevođeni na engleski, neki na francuski jezik, a neki nisu imali prevode. Od broja 16 za 1992. godinu svi su apstrakti prevođeni na engleski jezik. Posljednji objavljeni broj Novopazarskog zbornika je 38 za 2015. godinu.

16 Ejup Mušović, „Novi Pazar u prošlosti”, Novopazarski zbornik, br. 2, 1978, str. 7-14.

17 Breda Vlahović, „Pristup proučavanju kulture stanovanja u Novom Pazaru i okolini”, Novopazarski zbornik, br. 2, 1978, str. 15-22.

18 Milun Barjaktarević, „Uticaj Novog Pazara posredstvom materijalne kulture na severoistočne delove severa Crne Gore", Novopazarski zbornik, br. 2, 1978, str. 23-30. 
Novi Pazar je grad susreta civilizacija, kulturnih preplitanja, bogatog kulturnog nasljeđa. U njemu su neki od najznačajnijih vjerskih spomenika islamske ali i pravoslavne kulture našeg podneblja. Djela koja smo u ovom radu predstavili, a koja odslikavaju tu kulturnu, vjersku i civilizacijsku raznolikost novopazarskog kraja, samo su dio građe koja je digitalizacijom prikazana i predstavljaju virtuelnu zavičajnu zbirku koja se daljim radom mora dopunjavati i bogatiti.

\section{Literatura}

Barjaktarević, M., Uticaj Novog Pazara posredstvom materijalne kulture na severoistočne delove severa Crne Gore / Novopazarski zbornik. - Novi Pazar: Zavičajni muzej u Novom Pazaru, 1978. - str. 23-30.

Bejtić, M., Dvestoti broj 'Bratstva' / „Bratstvo” (Novi Pazar). - god. XII, br. 200 (10. jun 1956), str. 4.

Bejtić, M., Jovanović, B., Knežević, Đ. i dr., Novi Pazari okolina. - Beograd: Novinsko izdavačko preduzeće „Književne novine”, 1969.

Čar Drnda, H., Osnivanje Novog Pazara i njegov razvitak do kraja XVI stoleća / Novopazarski zbornik. - Novi Pazar: Zavičajni muzej u Novom Pazaru, 1984. - str. 77-102.

Čelebi, E., Putopis, odlomci o jugoslavenskim zemljama. - Sarajevo: Svjetlost, 1967.

Hadžiosmanović, L. i Memija, M., Poezija Bošnjaka na orijentalnim jezicima. - Sarajevo: Preporod, 1995.

Hasanagić, E., Novi dani / „Bratstvo” (Novi Pazar). - god. I, br. 1 (1. jun 1945), str. 1.

Jelenković, S., Sećanja / „Bratstvo” (Novi Pazar). - god. XII, br. 200 (10. jun 1956), str. 4.

Jovanović, R., U službi istine i progresa / „Bratstvo” (Novi Pazar). - god. XV, br. 300 (20. mart 1959), str. 1.

Kahrović, M., Novi Pazar u vaktu i zemanu. - Novi Pazar: Narodna biblioteka „Dositej Obradović", 2003.

Mušović, E., Novi Pazar u prošlosti / Novopazarski zbornik. - Novi Pazar: Zavičajni muzej u Novom Pazaru, 1978. - str. 7-14.

Mušović, E., Uvod / Novopazarski zbornik. - Novi Pazar: Zavičajni muzej u Novom Pazaru, 1977. - str. 3-4.

Nametak, F., Društvena uvjetovanost divanske književnosti / Bošnjačka književnost u književnoj kritici. - Sarajevo: Alef, 1998. - str. 464-480.

Palamarević, V., Obaveštenje / „Bratstvo” (Novi Pazar). - god. XXX, br. 1000 (16. novembar 1990), str. 1.

Salković, A., „Divan” Ahmeda Gurbija, književni biser i primarni istorijski izvor / Digitalizacije kulturne i naušne baštine: zbornik radova. - Beograd: Filološki fakultet, 2012. - str. 487-503.

Vali Novopazarac, A., Ljepota i srce. - Novi Pazar: Državni univerzitet u Novom Pazaru, 2009. 
Vlahović, B., Pristup proučavanju kulture stanovanja u Novom Pazaru i okolini / Novopazarski zbornik. - Novi Pazar: Zavičajni muzej u Novom Pazaru, 1978. - str. 15-22.

Zirojević, O., Novi Pazar u turskim izvorima do kraja XVI veka / Novopazarski zbornik. Novi Pazar: Zavičajni muzej u Novom Pazaru, 1977. - str. 111-119.

Zirojević, O., Srbija pod turskom vlašću: 1450-1804. - Beograd: Srpski genealoški centar, 2007.

\author{
Fuad Baćićanin \\ Avdija Salković \\ Emina Selmanović \\ National Library „Dositej Obradović” Novi Pazar
}

THE VIRTUAL HOMELAND COLLECTIONS - EXCHANGE OF CULTURES

\title{
Summary
}

The digitalised homeland collections, primarily those presenting the cultural wealth of a region with its specifics and characteristics, are a step towards the construction of a wealthy supranational and spaceless virtual library. Novi Pazar's region, a place where religions and cultures meet, is just beginig to represent its cultural inheritance to the wider scientific and cultural community.

In this paper we will present the cultural and literary content of Novi Pazar and its environs, through opus of digitalized native material, Divan written by Ahmed Gurbi, periodicals Bratstvo, and Novopazarski zbornik.

Divan literature, which evolved in the Balkans' area during the period of Ottoman authorities, contributed to the magnificent literary achievements. One of our most famous divan poets is Ahmed Gurubi, who wrote Divan in the Ottoman language, in the $18^{\text {th }}$ century in Novi Pazar. The initial part of Divan is Kasida o Novom Pazaru.

The periodical Bratstvo, which was published during the period from 1945 until 1991 in Novi Pazar, marked the birth, growth, but also the disappearing of a new period and culture.

Novopazarski zbornik is a magazine which was first published in the year of 1977 and which is still being published by the Ras museum of Novi Pazar. This magazine is primarily about the Ortodox past of Novi Pazar's region, as well as about its other cultural, religious and historical particularities.

By presenting a part of a digitalized homeland collection, in our paper we will point to the significance of virtual introduction and interweaving of cultural wealth.

Key words: Divan literature, virtual culture, homeland collections, historical sources 